\title{
Pensononowoor
}

2020 , vol. $83,60-67$

http://dx.doi.org/10.12657/denbio.083.006

\author{
Nguyen Thanh Tuan, Tai Tien Dinh*
}

\section{Growth performance of Dipterocarpus alatus and Hopea odorata in degraded secondary forest land in Southern Vietnam}

Received: 24 March 2020; Accepted: 14 July 2020

\begin{abstract}
The two dipterocarp species, Dipterocarpus alatus and Hopea odorata, have been widely planted in degraded forest land in Southern Vietnam in the last decades. However, study on growth characteristics of these species and their associated factors is still limited. Therefore, the present study aimed to examine growth performance in different stand densities, and classify tree quality in 28-year old $D$. alatus and $H$. odorata plantations. Our results of analysis of covariance (ANCOVA) indicated that in pure stand aged 28 years, $D$. alatus outperformed $H$. odorata in tree growth, biomass and volume. In addition, except for four growth variables including tree height at the first branch $(\mathrm{Hb})$, crown length $(\mathrm{CL})$, crown ratio $(\mathrm{CR})$ and linear crown index (LCI), the remaining variables were negatively affected by stand density. We observed that medium quality trees occupied the greatest proportion in both $D$. alatus $(47 \% ; \mathrm{n}=425)$ and $H$. odorata $(50 \% ; n=400)$. Except for CR and LCI, the class of good quality trees had the greatest values in the remaining examined growth variables. In linear discriminant analysis (LDA) model, the classification accuracy of testing set was relatively high in both D. alatus $(85 \%)$ and $H$. odorata $(91 \%)$. The most important variables for tree quality classification in $D$. alatus were crown diameter (CD) and diameter at breast height (DBH). Meanwhile, the most important variables in $H$. odorata were CD and tree height $(\mathrm{H})$. These obtained results suggest that controlling crown size is important for shaping individual tree quality. Our data evidenced that D. alatus and H. odorata planted in Southern Vietnam with density equal or less than 500 trees per ha could yield high proportion of good and medium quality trees.
\end{abstract}

Keywords: Dipterocarpus species, indigenous trees, aboveground biomass, tree biosocial position, tree quality classification

Addresses: Ng. Thanh Tuan, Department of Forestry Planning and Survey, Faculty of Forestry, Vietnam forestry University Southern campus, Vietnam, email: nttuan@vnuf2.edu.vn

T. Tien Dinh, Department of Environmental Informatics, Institute of Resources and Environment, Hue University, Vietnam, e-mail: dinhtientai@hueuni.edu.vn; tientai24990@gmail.com

${ }^{*}$ Corresponding author

\section{Introduction}

Vietnam is located in the Southeast Asia, lying between latitudes $8^{\circ} \mathrm{N}$ and $23^{\circ} \mathrm{N}$ and it has a total land area of about $330,000 \mathrm{~km}^{2}$. Over the last decades, forest resources in Vietnam considerably declined in terms of area and diversity (Salek \& Sloup, 2012). For instance, percentage of forest cover in Vietnam decreased from $43 \%$ in 1943 to $27 \%$ in 1990 (Vietnamese Government, 2001). Large-scale logging of primary forests and subsequent conversion of forests to agricultural lands are the main causes of forest 
degradation in Vietnam (Nguyen \& Gilmour, 1999; De Jong et al., 2006). In this context, Vietnam has made several attempts in forestry policy and practices for forest restoration and management (McNamara et al., 2006). Noticeably, afforestation has been widely implemented to increase forest cover and products in the country (De Jong et al., 2006). With several forest plantation programs, the total forest area in Vietnam has stabilized and then increased. In 2013, for instance, Vietnam's forest cover reached 13.96 million ha which occupied about $40.96 \%$ of the country's total area (FAO, 2014).

Forest plantation plays an important role not only in forest restoration and environmental services (Brown, 1999; West, 2014) but also in meeting the global demand for wood products that could triple by 2050 (Hakamada et al., 2017). In Vietnam, forest owners have reforested their land with high quality native species (Tam, 2007; Dong et al., 2016) and/ or fast-growing exotic species (Dong et al., 2014). Recently, reforestation efforts have focused on largescale monoculture plantations of native species, such as Dipterocarpus alatus, Hopea odorata (Dipterocarpaceae), Erythrophleum fordii (Leguminosae), Chukrasia tabularis, Toona surenii (Meliaceae), Canarium album (Burseraceae), Paulownia fortunei (Scrophulariaceae), Afzelia xylocarpa and Dalbergia spp. (Nghia, 2000).

Dipterocarp is a plant family of large tree species distributed widely in the tropical rain forests of Southeast Asia (Suzuki et al., 2006) that is considered as the richest ecosystems in terms of structure and species diversity (Kenzo et al., 2011; Tam et al., 2014). In Southern Vietnam, forest plantations of two dipterocarp species, Dipterocarpus alatus and Hopea odorata, have been established in different scales since the early 1930s (Nghia, 2003). Although some dipterocarp species (e.g., D. alatus and H. odorata,) have been widely planted (Appanah \& Weinland, 1993; Appanah \& Turnbull, 1998), knowledge on their growth and associated factors remains limited (Sakai et al., 2014). Lack of knowledge on growth characteristics of dipterocarp species may lead to the failure in reforestation. For instance, plantation of $H$. odorata in some areas of Vietnam had failed because of inappropriateness in planting sites and silvicultural treatment (Tam, 2007).

Previous studies have concerned with growth performance of dipterocarp plantation in degraded forest lands but mostly focused on growth stage of less than 20 years (Hamzah et al., 2009). Little is known about growth characteristics of dipterocarp plantation in old stand. Among tree growth variables, tree biomass is an important metric for determining the carbon storage, forest yield and estimating flammable materials in forest fires (de-Miguel et al., 2014). Estimation of aboveground biomass (AGB) is essential for studying carbon stocks (Ketterings et al., 2001) and comparing structural and functional attributes of forest ecosystems (Brown, 2002). In the present study, we therefore aimed to (1) evaluate the growth characteristics and aboveground biomass of $D$. alatus and $H$. odorata plantations in different stand densities on degraded forest land and (2) determined relative importance of growth variables on tree quality classification.

\section{Materials and methods}

\section{Study site and data collection}

The study site is Chang Riec Historical and Cultural Forest in Tay Ninh province in the Southwest region of Vietnam. In 1990, two dipterocarp species, $H$. odorata and $D$. alatus, were purely planted with different stand densities. Specifically, each species was initially planted in $10-\mathrm{m}$ rows $\times 2.5$-m columns and $8-\mathrm{m}$ rows $\times 2.5 \mathrm{~m}$-columns that yielded of 400 and 500 trees per hectare, respectively. The planting site $\left(11^{\circ} 35.13^{\prime} \mathrm{N}, 106^{\circ} 07.10^{\prime} \mathrm{E}\right)$ has mean altitude of $50 \mathrm{~m}$. The study site has two distinct seasons, including the dry season from December to April and the rainy season from May to November. The mean annual temperature is about $26^{\circ} \mathrm{C}$ and mean annual humidity is about $80 \%$. The mean annual precipitation is $1967 \mathrm{~mm}$ with the average number of rainy days of about 154 days (IBST, 2009). The soil in the study site is ferralsols developed from acid magma and old alluvia.

To evaluate the growth performance of $D$. alatus and $H$. odorata plantations, three plots $(50 \times 40 \mathrm{~m}$ each) were randomly established within each stand of different densities which was homogeneous in environmental conditions (e.g., slope, aspect, elevation and soil type). In total, 12 plots ( 3 plots $\times 2$ initial stand densities $\times 2$ species) were set up for measurement. In spring 2017, we surveyed and measured all trees in 12 plots. It is noting that the density in these plots was not the same as the initial planting density due to mortality. Since the planting time, there were no treatments and/or disasters (e.g., storms, wildfires) in the planting site, thus the decrease in stand density may be due to natural thinning. Mortality percentage of these 12 plots ranged from 17.5 to $28.0 \%$ with mean value of $23.4 \%$. Mortality proportion of $\mathrm{H}$. odorata $(25.7 \%)$ was higher than that (21.0\%) of D. alatus (Wilcoxon rank-sum test, $P$-value $=0.012$ ). Meanwhile, mortality did not statistically differ between initial planting densities ( $P$-value $=0.091$ ). In this study, we used recent surveyed density as the variable in all statistical analyses. All trees within each plot were measured for total tree height $(\mathrm{H})$, tree height at the first branch $(\mathrm{Hb})$, diameter at breast height $(\mathrm{DBH})$ and crown diameter (CD). The $\mathrm{CD}$ of a tree individual was measured as the greatest 
Table 1. Criteria for tree quality classification

\begin{tabular}{|c|c|c|c|c|}
\hline Quality class & Stem form & Crown shape & Sociological position & Plant health \\
\hline The first-good & Straight & Symmetric fully developed & Upper & Good health \\
\hline The second-medium & Slightly tortuous & $\begin{array}{l}\text { Asymmetric fully developed } \\
\text { or deformed fully developed }\end{array}$ & Medium & Medium health \\
\hline The third-bad & Tortuous & Undeveloped, flattened & Lower & $\begin{array}{l}\text { Poor health, insect pest } \\
\text { attack, rotten stem }\end{array}$ \\
\hline
\end{tabular}

spread of crown projection. Tree height was measured using the Häglof Vertex Hypsometer and DBH was measured using diameter tape. Based on criteria of stem form, crown shape, sociological position and plant health (Kupka et al., 2018; Roik et al., 2018), the quality of all trees within plot was classified into three quality classes (Table 1 ).

Tree volume $\left(\mathrm{V}, \mathrm{m}^{3}\right)$ was calculated using the following equation (Eq.1) (Ostadhashemi et al., 2014):

$$
\mathrm{V}=\mathrm{BA}_{1.3} \times \mathrm{H} \times \mathrm{f}_{1.3}
$$

in which $\mathrm{V}$ is stem volume $\left(\mathrm{m}^{3}\right), \mathrm{BA}_{1.3}$ is basal area at $\mathrm{DBH}\left(\mathrm{m}^{2}\right), \mathrm{H}$ is total tree height $(\mathrm{m})$ and $\mathrm{f}_{1.3}$ is form factor $\left(\mathrm{f}_{1.3}=0.5\right)$.

The important structural variables in relation to tree crown are crown length $(\mathrm{CL}, \mathrm{m})$, crown projection area $\left(\mathrm{CPA}, \mathrm{m}^{2}\right)$, crown ratio (CR), crown spread ratio (CSR), crown thickness index (CTI) and linear crown index (LCI) that were respectively calculated using Eq. 2, Eq. 3, Eq. 4, Eq. 5, Eq. 6 and Eq. 7 (Van Laar \& Akça, 2007).

$$
\begin{gathered}
\mathrm{CL}=\mathrm{H}-\mathrm{Hb} \\
\mathrm{CPA}=\mathrm{CD}^{2} \frac{\pi}{4} \\
\mathrm{CR}=\frac{\mathrm{CL}}{\mathrm{H}} \\
\mathrm{CSR}=\frac{\mathrm{CD}}{\mathrm{H}} \\
\mathrm{CTI}=\frac{\mathrm{CD}}{\mathrm{CL}} \\
\mathrm{LCI}=\frac{\mathrm{CD}}{\mathrm{DBH}}
\end{gathered}
$$

In each species, the average DBH value of trees in each forest plot was calculated. In each plot, we then selected 3 sample trees having DBH closest to its average $\mathrm{DBH}$ value for aboveground biomass (AGB) estimation. In spring 2017, the chosen trees were felled down and divided into branches, twigs, stem and foliage components, and then weighed on field. The total aboveground biomass was determined as the sum of the stems, branches and leaves weights.

\section{Statistical analysis}

Analysis of Covariance (ANCOVA) was used to examine the effect of species and stand density on tree growth and aboveground biomass. Furthermore, one-way ANOVA was employed to test the difference in growth variables between tree quality classes. We used Tukey's HSD as the post-hoc analysis to identify statistical differences among tree quality classes. Statistical significance in all analyses was determined at $\alpha=0.05$.

In our study, Linear Discriminant Analysis (LDA) was employed for constructing tree quality classification model based on four growth variables including tree height $(\mathrm{H})$, crown length $(\mathrm{CL})$, diameter at breast height (DBH) and crown diameter (CD). These traits are easy to measure and have been used in previous work (Nigh \& Love, 2004; Kaźmierczak \& Zawieja, 2016). Our data were split in two subsets including a training set $(60 \%)$ and a testing set $(40 \%)$. The training set was used to fit the model and the testing set was used to evaluate the accuracy of the model. The LDA analysis was implemented using the package MASS (Venables \& Ripley, 2002) in $\mathrm{R}$ version 3.6.2 (R Core Team, 2019).

\section{Results}

\section{Growth and aboveground biomass of D. alatus and $H$. odorata}

The average values of tree growth variables in the two species were described in the Supplementary Table S1. Except for crown spread ratio (CSR), crown thickness index (CTI) and linear crown index (LCI), the remaining 12 tree growth variables of $H$. odorata were significantly smaller than that of $D$. alatus (Table 2). For instance, $H$. odorata had about $4 \mathrm{~cm}$ and $0.11 \mathrm{~m}^{3}$ smaller DBH and tree volume, respectively, compared with $D$. alatus. Regarding total biomass, $H$. odorata was $109.89 \mathrm{~kg}$ lower than that of $D$. alatus. In contrast, it appeared that LCI and CTI of $H$. odorata were respectively 3.72 and 0.04 greater than those of $D$. alatus, while CSR was not significantly different between these two species.

We found that crown length (CL), crown ratio (CR) and linear crown index (LCI) were not significantly affected by stand density while tree height at 
Table 2. The effects of species and stand density on tree growth characteristics and aboveground biomass using analysis of covariance (ANCOVA)

\begin{tabular}{|c|c|c|}
\hline \multirow{2}{*}{ Response variables } & \multicolumn{2}{|c|}{ Coefficient estimates (SE); Eta-squared } \\
\hline & Species (H. odorata compared with D. alatus) & Stand density \\
\hline Diameter at breast height - DBH $(\mathrm{cm})$ & $-4.00(0.35)^{* * *} ; 0.092$ & $-0.04(0.01)^{* * *} ; 0.044$ \\
\hline Tree height $-\mathrm{H}(\mathrm{m})$ & $-0.86(0.06)^{* * *} ; 0.059$ & $-0.01(0.001)^{* * *} ; 0.012$ \\
\hline Tree height at first branch $-\mathrm{Hb}(\mathrm{m})$ & $-0.19(0.08)^{*} ; 0.004$ & $0.01(0.001)^{* *} ; 0.008$ \\
\hline Crown diameter - CD (m) & $-0.28(0.06)^{* * *} ; 0.011$ & $-0.004(0.001)^{* * *} ; 0.073$ \\
\hline Crown length - CL (m) & $-0.63(0.08)^{* * *}$ & \\
\hline Crown projection area - CPA $\left(\mathrm{m}^{2}\right)$ & $-2.76(0.55)^{* * *} ; 0.018$ & $-0.10(0.01)^{* * * *} ; 0.098$ \\
\hline Crown ratio $-\mathrm{CR}$ & $-1.82(0.52)^{* *}$ & \\
\hline Crown spread ratio - CSR & & $-0.07(0.006)^{* * *}$ \\
\hline Crown thickness index - CTI & $0.04(0.01)^{* * *} ; 0.006$ & $-0.001(0.0002)^{* * *} ; 0.043$ \\
\hline Linear crown index - LCI & $3.72(0.27)^{* * *}$ & \\
\hline Foliage biomass (kg) & $-10.20(1.21)^{* * *} ; 0.28$ & $-0.11(0.02)^{* * *} ; 0.12$ \\
\hline Branch biomass (kg) & $-3.16(1.33)^{*} ; 0.02$ & $-0.16(0.02)^{* * *} ; 0.19$ \\
\hline Stem biomass $(\mathrm{kg})$ & $-96.53(5.91)^{* * *} ; 0.53$ & $-0.34(0.09)^{* *} ; 0.02$ \\
\hline Total fresh biomass - AGB $(\mathrm{kg})$ & $-109.89(6.74)^{* * *} ; 0.42$ & $-0.61(0.11)^{* * *} ; 0.05$ \\
\hline Tree volume $-\mathrm{V}\left(\mathrm{m}^{3}\right)$ & $-0.110(0.008)^{* * *} ; 0.12$ & $-0.001(0.0001)^{* * *} ; 0.05$ \\
\hline
\end{tabular}

${ }^{*}-P<0.05$; ** $-P<0.01$; ${ }^{* *}-P<0.001$.

the first branch $(\mathrm{Hb})$ of both species increased with stand density. The remaining tree growth, biomass and volume variables of $D$. alatus and $H$. odorata significantly decreased with increasing stand density (Table 2). In both species, for instance, a one-unit (one tree) increase of stand density could result in a decrease of $0.04 \mathrm{~cm}$ and $0.001 \mathrm{~m}^{3}$ in $\mathrm{DBH}$ and tree volume, respectively.

In this study, we used eta-squared as a criterion to determine relative importance variables in ANCOVA model. Our results showed that the relative importance of two predictors (species and stand density) varied with examined variables. For DBH and tree volume, species variable showed higher eta-squared values (0.092 and 0.120 , respectively) than that (0.044 and 0.05) of stand density. In contrast, for crown diameter, crown projection area and branch biomass, stand density had greater eta-squared values than that of species variable.

The medium quality class occupied the highest proportion in both $D$. alatus $(47 \% ; \mathrm{n}=425)$ and $H$. odorata $(50 \% ; n=400)$. Using pooled data of both species, we found that the first class (good quality trees) had the greatest values, following by the second class (medium quality trees) for all examined growth and volume variables, except for $\mathrm{CR}$ and LCI (Table 3). We observed that crown ratio (CR) in all three classes was, on average, equal or greater than 0.47 and no statistical significance was found between them. Linear crown index (LCI) of the first quality class (0.23) was significantly smaller than that of the second (0.26) and third classes (0.26).

\section{Tree quality classification}

In each species, average values of four examined variables were not significantly different between training and testing sets (Supplementary Table S2). The LDA model showed that the first linear discriminant function (LD1) explained much percentage

Table 4. Linear discriminant functions

\begin{tabular}{lcccr}
\hline \multirow{2}{*}{\multicolumn{1}{c}{ Predictor }} & \multicolumn{4}{c}{$\begin{array}{c}\text { Coefficient estimates of linear } \\
\text { discriminants }\end{array}$} \\
\cline { 2 - 5 } & \multicolumn{3}{c}{ D. alatus } & \multicolumn{1}{c}{ H. odorata } \\
\cline { 2 - 5 } & LD1 & LD2 & LD1 & LD2 \\
\hline DBH (cm) & 0.165 & 0.303 & 0.17 & 0.28 \\
Tree height (m) & 0.009 & 0.518 & 0.50 & -0.15 \\
Crown diameter (m) & 1.252 & -1.682 & 1.51 & -1.47 \\
Crown length (m) & 0.121 & -0.312 & -0.01 & 0.64 \\
Percent of separation & $97.7 \%$ & $2.3 \%$ & $98.5 \%$ & $1.5 \%$ \\
explained & & & & \\
\hline
\end{tabular}

LD1 and LD2 are the first and second linear discriminants in LDA model.

Table 3. Comparison of tree growth and volume variables among quality classes using pooled data of both species

\begin{tabular}{|c|c|c|c|c|c|c|c|c|c|c|c|}
\hline \multirow{2}{*}{$\begin{array}{l}\text { Quality } \\
\text { classes }\end{array}$} & \multicolumn{11}{|c|}{ Growth variables } \\
\hline & $\mathrm{DBH}(\mathrm{cm})$ & $\mathrm{H}(\mathrm{m})$ & $\mathrm{Hb}(\mathrm{m})$ & $\mathrm{V}\left(\mathrm{m}^{3}\right)$ & $\mathrm{CD}(\mathrm{m})$ & $\mathrm{CPA}\left(\mathrm{m}^{2}\right)$ & $\mathrm{CR}$ & CSR & CTI & LCI & $\mathrm{CL}(\mathrm{m})$ \\
\hline $1^{\text {st }}(\mathrm{n}=189)$ & $28.3^{a}$ & $14.6^{a}$ & $7.5^{\mathrm{a}}$ & $0.45^{\mathrm{a}}$ & $6.5^{\mathrm{a}}$ & $33.2^{\mathrm{a}}$ & $0.48^{\mathrm{a}}$ & $0.44^{\mathrm{a}}$ & $1.0^{\mathrm{a}}$ & $0.23^{\mathrm{b}}$ & $7.1^{\mathrm{a}}$ \\
\hline $2^{\text {nd }}(n=441)$ & $22.1^{\mathrm{b}}$ & $13.7^{\mathrm{b}}$ & $7.2^{\mathrm{b}}$ & $0.27^{\mathrm{b}}$ & $5.7^{\mathrm{b}}$ & $25.4^{\mathrm{b}}$ & $0.47^{\mathrm{a}}$ & $0.41^{\mathrm{b}}$ & $0.9^{\mathrm{b}}$ & $0.26^{\mathrm{a}}$ & $6.5^{\mathrm{b}}$ \\
\hline $3^{\text {rd }}(n=195)$ & $16.8^{c}$ & $13.0^{c}$ & $6.7^{\mathrm{b}}$ & $0.16^{c}$ & $4.3^{c}$ & $14.5^{\mathrm{c}}$ & $0.48^{\mathrm{a}}$ & $0.33^{c}$ & $0.7^{\mathrm{c}}$ & $0.26^{\mathrm{a}}$ & $6.2^{c}$ \\
\hline
\end{tabular}

Different letters indicate statistical significance among quality classes. Tukey's HSD was used as post-hoc test. The $1^{\text {st }}, 2^{\text {nd }}$ and $3^{\text {rd }}$ correspond to good, medium and bad quality classes, respectively. 

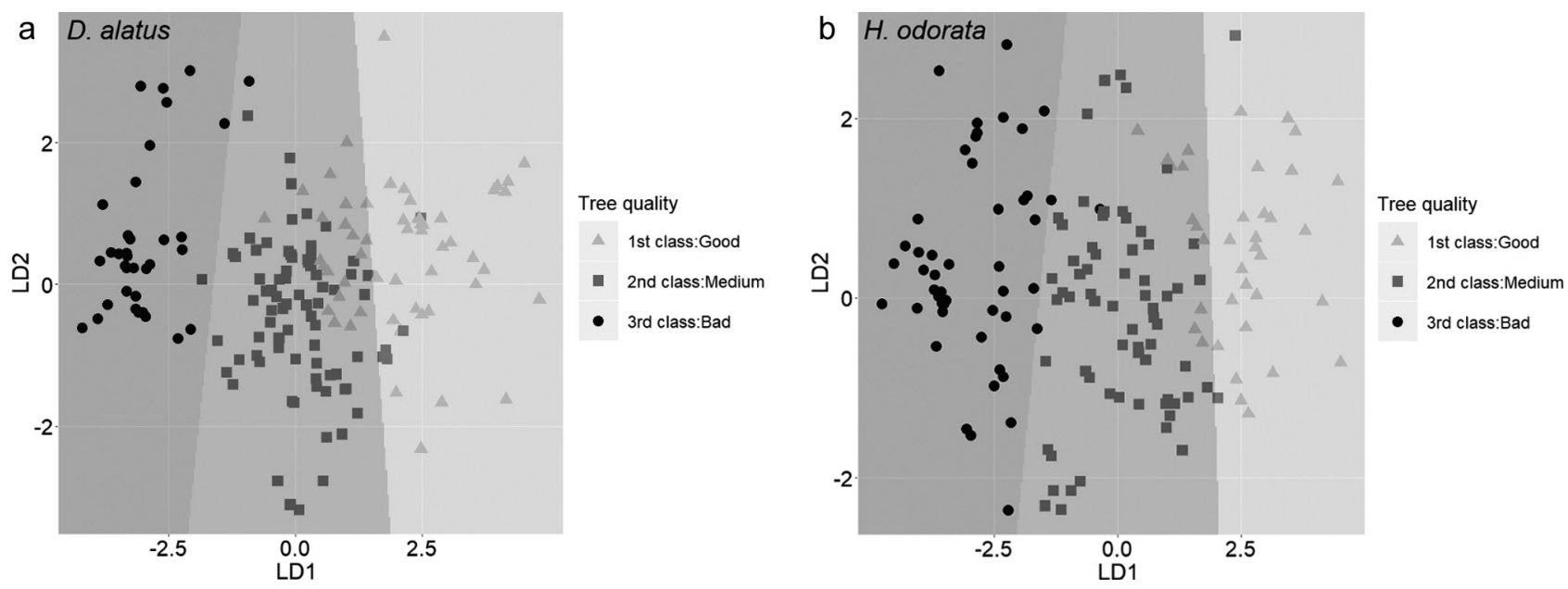

Fig. 1. Linear discrimination functions for tree quality classification in (a) D. alatus, and (b) H. odorata. Point shapes and shade regions indicate tree quality classes. Points show tree individuals in testing set

separation between tree quality classes in both $D$. alatus $(97.7 \%)$ and $H$. odorata $(98.5 \%)$. In D. alatus, the crown diameter, DBH and crown length had the highest contributions as indicated by their coefficients in LD1 for discriminating between quality classes (Table 4; Figure 1). In H. odorata, however, the most important variables in LD1 were crown diameter and tree height. Using four predictor variables, the LDA model of $D$. alatus performed relatively well with prediction accuracy of 87 and $85 \%$ in training and testing sets, respectively. Meanwhile, these accuracy numbers in LDA model of $H$. odorata were respectively 94 and $91 \%$.

\section{Discussions}

Selection of the suitable species is necessary for successfully restoring degraded forests (Yousefi et al., 2013). On the contrary to the argument that dipterocarp species may not be suitable for rehabilitation of severely degraded lands (Appanah \& Tumbull, 1998; Tolentino, 2008), our results demonstrated that $D$. alatus and $\mathrm{H}$. odorata can be used for restoration of degraded forest land because they could have high proportion of good and medium quality trees (Table 3 ).

We compared our obtained results with previous work that studied $D$. alatus and $H$. odorata under different stand densities, ages, and planting techniques (Supplementary Table S3). Our result is consistent with the finding of Nghia (2003) who showed that $D$. alatus exhibited greater $\mathrm{DBH}$ and tree height than $H$. odorata in pure plantation (416 trees per ha) in Southern Vietnam. Furthermore, we found that $D$. alatus had higher values in other tree growth variables (i.e., Hb, CD, CL, CPA and CR), aboveground biomass and tree volume. Thus, our data provided evidence that in pure stand, $D$. alatus may outperform $H$. odorata in tree growth.
Several studies have shown that tree growth could be affected by stand density in dipterocarp (Rahman et al., 2016) and other species (Navarro et al., 2010; Jaouadi et al., 2018; Nguyen et al., 2019). In accordance with previous work, we observed that stand density negatively affected DBH in both $D$. alatus and H. odorata (Nghia, 2003; Hong et al., 2012). In Southern Vietnam, for instance, Nghia (2003) showed that $\mathrm{DBH}$ of $D$. alatus at age 17 years was about 22.4 and $17.2 \mathrm{~cm}$ in stand density of 416 and 1000 trees per ha, respectively. Meanwhile, DBH of $H$. odorata at age 18 years was 18.7 and $14.6 \mathrm{~cm}$ in stand density of 1100 and 2500 trees per ha, respectively (Table S3).

The effect of stand density on tree height is often modest (Nguyen et al., 2019; Jiang et al., 2007). For instance, Hong et al. (2012) found no significant effect of stand density on tree height in D. alatus and $\mathrm{H}$. odorata in 9-year old stand. In our study, however, tree height tended to slightly decrease with increasing stand density in both species in 28-year old stands. This inconsistency in the obtained result between our study and Hong et al. (2012) could be attributed to the difference in age and environmental conditions. Our finding is supported by Nghia (2003) who observed a slightly greater height of $\mathrm{H}$. odorata in stand density of 1100 trees per ha, compared with that in density of 2500 trees per ha. Noticeably, tree height at the first branch $(\mathrm{Hb})$ was positively affected by stand density. Branches may greatly compete for light under high density condition, whereby increasing natural branch pruning and thus increasing tree height at the first branch.

We found that stem occupied the highest proportion of biomass in $H$. odorata $(76.01 \%$; equivalent to $256 \mathrm{~kg}$ per tree) and D. alatus (79.61\%; $346 \mathrm{~kg}$ per tree). The biomass contributions of branches and leaves in $H$. odorata were 15.74 and $8.25 \%$, respectively. Meanwhile, these numbers in $D$. alatus were 
12.14 and $8.25 \%$, respectively. Our obtained results were in accordance with other work indicating the greatest contribution of stem biomass to above ground biomass. For instance, in 19-year old D. alatus stand with density of 2425 trees per ha, Peawsa-ad and Viriyabuncha (2002) showed that biomass in stem, branches and leaves was 47.01, 8.94 and 2.35 $\mathrm{kg}$, respectively. Kusno et al. (2012) reported that in H. odorata stand of 1350 trees per ha at age 11 years, biomass of stem, branches and leaves was 82.69, $6.12,2.95 \mathrm{~kg}$, respectively. In our study, a greater individual tree biomass was observed in lower density stand for both $D$. alatus and $H$. odorata. This result may be owing to severe competition for nutrient and light in high density stand.

It has been argued that tree biosocial position could be highly correlated with tree traits and can affect tree growth and development (Tomczak, 2013). Previous studies have attempted to classify tree biosocial position (Kaźmierczak \& Zawieja, 2016). In our study, we focused on tree quality classification using LDA analysis with four tree variables including $\mathrm{DBH}$, tree height, crown diameter and crown length. Our LDA models indicated that crown diameter was the most important variable in the first linear discriminant function (LD1) for determining tree quality class in both $D$. alatus and $H$. odorata. This result supported the finding of Kaźmierczak and Zawieja (2016) who showed that tree crown size highly influenced tree biosocial and quality. Crown size may affect light capture capacity and photosynthesis process (Choi et al., 2001; Kaźmierczak \& Zawieja, 2016), by which influencing tree growth and quality. The LDA model had a high classification accuracy for testing set in both $D$. alatus $(85 \%)$ and $H$. odorata $(91 \%)$, suggesting that the model can be used to determine tree quality of these species.

\section{Conclusions}

The present study provides evidence that both species, $D$. alatus and $H$. odorata, planted with density equal or less than 500 trees per ha could yield high proportion of good and medium quality trees at age of 28 years in Southern Vietnam. Tree growth variables and biomass can vary with species and stand density. Our study suggests that controlling crown development is important for shaping individual tree quality.

\section{Acknowledgments}

The authors would like to thank Mr. Nguyen Xuan Hanh and Mr. Vuong Cong Ty for assistance in field measurement.

\section{References}

Appanah S \& Turnbull JM (1998) A review of dipterocarps: Taxonomy, ecology and silviculture. CIFOR, Bogor, Indonesia.

Appanah S \& Weinland G (1993) Planting quality timber trees in Peninsular Malaysia: a review. Malayan Forest Record No. 38. Forest Research Institute Malaysia, Kuala Lumpur.

Brown S (1999) Opportunities for mitigating carbon emission through forestry activities. Winrock International, Airlington, V.A., USA.

Brown S (2002) Measuring, monitoring, and verification of carbon benefits for forest-based projects. Philosophical Transactions of the Royal Society of London. Series A: Mathematical, Physical and Engineering Sciences 360: 1669-1683.

Choi J, Lorimer CG, Vanderwerker J, Cole WG \& Martin GL (2001) A crown model for simulating long-term stand and gap dynamics in northern hardwood forests. Forest Ecology and Management 152: 235-258.

De Jong W, Sam DD \& Van HT (2006) Forest rehabilitation in Vietnam: Histories, realities, and future. Center for International Forestry Research (CIFOR), Bogor, Indonesia.

de-Miguel S, Mehtätalo L \& Durkaya A (2014) Developing generalized, calibratable, mixed-effects meta-models for large-scale biomass prediction. Canadian Journal of Forest Research 44: 648-656.

Dong TL, Beadle C, Eyles A, Forrester DI, Doyle R, Worledge D \& Khanh DC (2016) Growth and physiology of Hopea odorata planted within gaps in an acacia plantation acting as a nurse crop. Plant Ecology \& Diversity 9: 549-562.

Dong TL, Doyle R, Beadle CL, Corkrey R \& Quat NX (2014) Impact of short-rotation Acacia hybrid plantations on soil properties of degraded lands in Central Vietnam. Soil Research 52: 271-281.

Food and Agriculture Organization of the United Nations (FAO) (2014) Global Forest Resource Assessment 2015: Country Report Viet Nam. Rome, Italy.

Hakamada R, Hubbard RM, Ferraz S, Stape JL \& Lemos C (2017) Biomass production and potential water stress increase with planting density in four highly productive clonal Eucalyptus genotypes. Southern Forests: Journal of Forest Science 79: 251-257.

Hamzah MZ, Arifin A, Zaidey AK, Azirim AN, Zahari I, Hazandy AH \& Nik Muhamad M (2009) Characterizing soil nutrient status and growth performance of planted dipterocap and non-dipterocarp species on degraded forest land in Peninsular Malaysia. Journal of Applied Sciences 9: 4215-4223.

Hong NTH, Le NT, Phuong DX, Thoi HV \& Cao TT (2012) The results of a survey of the growth and 
development of Hopea odorata Roxb and Dipterocarpus alatus Roxb. plantations in the southeast, south central and highlands. Conference on Forestry Science and Technology with Sustainable Forest Development and Climate Change. Ha Noi, Viet nam, 218-224.

IBST (2009) Vietnam building code natural physical \& climatic data for construction. QCVN 02:2009/ BXD. Institute for Building Science and Technology (IBST), Vietnam.

Jaouadi W, Mechergui K, Riahi MA \& Khouja M L (2018) Effect of thinning on Pinus pinea L. development and physico-chemical soil characteristics in northwestern Tunisia: modeling of radial growth under thinning intensity. Dendrobiology 80: 70-80.

Jiang ZH, Wang XQ, Fei BH, Ren HQ \& Liu XE (2007) Effect of stand and tree attributes on growth and wood quality characteristics from a spacing trial with Populus xiaohei. Annals of Forest Science 64: 807-814.

Kaźmierczak K \& Zawieja B (2016) Tree crown size as a measure of tree biosocial position in 135-yearold oak (Quercus L.) stand. Folia Forestalia Polonica 58: 31-42.

Kenzo T, Yoneda R, Matsumoto Y, Azani AM \& Majid MN (2011) Growth and photosynthetic response of four Malaysian indigenous tree species under different light conditions. Journal of Tropical Forest Science 23: 271-281.

Ketterings QM, Coe R, van Noordwijk M \& Palm CA (2001) Reducing uncertainty in the use of allometric biomass equations for predicting above-ground tree biomass in mixed secondary forests. Forest Ecology and Management 146: 199-209.

Kupka I, Baláš M \& Miltner S (2018) Quantitative and qualitative evaluation of Northern red oak (Quercus rubra L.) in arid areas of North-Western Bohemia. Journal of Forest Science 64: 53-58.

Kusno MA, Abdul-Hamid H, Senin AL, Heriansyah I \& Ismail M K (2012) Allometric Equation for Biomass Estimation of Hopea odorata Stands in Pahang, Malaysia. Conference: International Symposium on Reclamation, Rehabilitation and Restoration, Kuala Lumpur.

McNamara S, Tinh DV, Erskine PD, Lamb D, Yates D \& Brown S (2006) Rehabilitating degraded forest land in central Vietnam with mixed native species plantings. Forest Ecology and Management 233: 358-365.

Navarro FB, Jiménez MN, Cañadas EM, Gallego E, Terrón L, Ripoll MA (2010) Effects of different intensities of overstory thinning on tree growth and understory plant-species productivity in a semi-arid Pinus halepensis Mill. afforestation. Forest Systems 3: 410-417.
Nghia NH (2000) Use of native species in forest rehabilitation and conservation in Vietnam: Proceedings of the Workshop on Forest Restoration for Wildlife Conservation 30: 105-107.

Nghia NH (2003) Dipterocarp species in Vietnam. In Proceedings of the Seventh Roundtable Conference on Dipterocarps, Kuala Lumpur, Malaysia, pp73-79.

Nguyen MT \& Ta DL (2016) Evaluating the growth rates of some native species under the forest canopy in Soc Son, Ha Noi. Vietnam Journal of Forest Science 3: 4482-4489.

Nguyen TT, Tai DT, Zhang P, Razaq M \& Shen H L (2019) Effect of thinning intensity on tree growth and temporal variation of seed and cone production in a Pinus koraiensis plantation. Journal of Forestry Research 30: 835-845.

Nguyen VS \& Gilmour D (1999) Forest rehabilitation policy and practice in Vietnam. National Workshop. IUCN, Hoa Binh, Vietnam.

Nigh GD \& Love BA (2004) Predicting crown class in three western conifer species. Canadian Journal of Forest Research 34: 592-599.

Ostadhashemi R, Shahraji TR, Roehle H \& Limaei SM (2014) Estimation of biomass and carbon storage of tree plantations in northern Iran. Journal of forest science 60: 363-371.

Peawsa-ad K \& Viriyabuncha C (2002) Growth and yield and aboveground biomass of Dipterocarpus alatus aged 19 yrs: 7. Proceedings of the silvicultural seminar: Silviculture for commercial plantations, Bangkok, Thailand.

Pham VB (2009) Primary appraisal of growth of Erythrophloeum fordii Oliv in binh phuoc province. Vietnam Journal of Forest Science 3: 4482-4489.

R Core Team (2019) R: A language and environment for statistical computing. R Foundation for Statistical Computing, Vienna, Austria.

Rahman KA, Afizzul MM, Niiyama K, Iida S, Kimura K, Sato T \& Azizi R (2016) Predicting annual stem diameter increment of major tree species in mixed hill dipterocarp forest with consideration on tree and stand level effects. Journal of Tropical Forest Science 28: 359-368.

Roik M, Machado SDA, Figueiredo Filho A, Sanquetta CR, Roveda M \& Stepka TF (2018) Diameter increment modeling in an Araucaria forest fragment using cluster analysis. Floresta e Ambiente 25: e20170625.

Sakai A, Visaratana T, Vacharangkura T, Thai-Ngam R \& Nakamura S (2014) Growth performance of four dipterocarp species planted in a Leucaena leucocephala plantation and in an open site on degraded land under a tropical monsoon climate. Japan Agricultural Research Quarterly 48: 95-104.

Salek L \& Sloup R (2012) Economic evaluation of proposed pure and mixed stands in Central Viet- 
nam highlands. Journal of Agriculture and Rural Development in the Tropics and Subtropics 113: $21-29$.

Suzuki K, Ishii K, Sakurai S \& Sasaki S (2006) Plantation technology in tropical forest science. Springer Tokyo.

Tam NM, Duy VD, Duc NM, Giap VD \& Xuan BTT (2014) Genetic variation in and spatial structure of natural populations of Dipterocarpus alatus (Dipterocarpaceae) determined using single sequence repeat markers. Genetics and Molecular Research 13: 5378-5386.

Tam PD (2007) Assessment of watershed protection plantations of mixed Acacia and native species in the five million-hectare-reforestation program. Hanoi: Forest Science Institute of Vietnam.

To BT, Bui VH, Pham XH (2014) Effects of planting factors in growth of dipterocarpaceae species in forest restoration models in Dong Nai province. Vietnam Journal of Forest Science 3: 3433-3441.

Tolentino EL (2008) Restoration of Philippine native forest by smallholder tree farmers: Smallholder tree growing for rural development and environmental services. Springer, Dordrecht, pp. 319-346.

Tomczak A (2013) Selected technical parameters of juvenile wood in Scots pine (Pinus sylvestris L.) variation between social classes of tree position in the dominant stand. Acta Scientarum Polonorum, Silvarum Colendarum Ratio et Industria Lignaria 12: $43-53$.

Van Laar A \& Akça A (2007) Forest mensuration. Managing Forest Ecosystems: Vol. 13. Springer Science \& Business Media.

Venables WN \& Ripley BD (2002) Modern applied statistics with S. 4th ed. Springer, New York.

Vietnamese Government (2001) Decision No. 03/2001/QD-TTg dated January 05, 2001 of the Prime Minister approving the results of general inventory of forests throughout the country.

Vo DH \& Hoang PM (2014) Research on protection forest planting techniques in coastal hilly-mountainous areas, Phu Yen province. Vietnam Journal of Forest Science 1: 3119-3129.

West PW (2014) Growing plantation forests. Springer-Verlag.

Yousefi M, Pourmajidian MR, Karimi M \& Darvishi L (2013) Quantitative and qualitative evaluation of forest plantations by four species and suggestion the appropriate species in the Hyrcanian forest. European Journal of Experimental Biology 3: 352-360. 